\title{
Neural defects and cardiac arrhythmia in fish larvae following embryonic exposure to 2,2',4,4'-tetrabromodiphenyl ether (PBDE 47)
}

\author{
Sean C. Lema Irvin R. Schultz Nathaniel L. Scholz \\ John P. Incardona Penny Swanson
}

\begin{abstract}
Polybrominated diphenyl ethers (PBDEs) are added to plastics, polyurethane foam, and textiles as a flame retardant. While PBDEs play a key role in reducing loss of human life and property from fires, these flame retardants have become pervasive organic contaminants in the environment and in the tissues of fish, birds, marine mammals, and humans. Levels of PBDEs in wildlife and humans continue to rise, raising concerns about potential ecological and health risks associated with exposure to these chemicals. Nevertheless, there is little currently known about the toxicological effects of PBDE exposure. Here, we examined the developmental toxicity of the PBDE congener 2,2',4,4'-tetrabromodiphenyl ether (PBDE 47) using the zebrafish (Danio rerio) as an ontogenetic model. Zebrafish embryos were exposed continuously to dissolved phase PBDE 47 (100-5000 $\mu \mathrm{g} / \mathrm{l}$ ) beginning 3-5 h post-fertilization (hpf). Fish treated with the highest concentrations of PBDE 47 delayed hatching, had reduced growth posthatching, and displayed an abnormal dorsal curvature of the body with flexion at the hindbrain. By $96 \mathrm{~h}$ post-fertilization larvae exposed to PBDE 47 had significant tachycardia, which progressed into atrioventricular block arrhythmias. Microinjection of fluorescent dye into the hindbrain ventricle revealed that cerebrospinal fluid in the neural tube and brain ventricles flowed more slowly in fish larvae exposed to PBDE 47, a likely etiology for the dorsal curvature. Similar, though much less pronounced, developmental toxicity also occurred in larvae exposed to PBDE 47 only for a $20 \mathrm{~h}$ period during early embryogenesis (3-23 hpf), suggesting that PBDEs incorporated in lipid of the egg are bioavailable and cause toxicity later in life. Taken together, this work indicates that exposure to PBDE 47 can cause morphological abnormalities, impair cardiovascular function and cerebrospinal fluid flow, and provides a tractable starting point for using the zebrafish model to explore molecular mechanisms of PBDE toxicity.
\end{abstract}

Keywords: Polybrominated diphenyl ethers; PBDE; Brominated flame retardants; Development; Persistent organic pollutants; Fire retardants; Brain; Zebrafish

\section{Introduction}

Polybrominated diphenyl ethers (PBDEs) are a group of brominated hydrocarbons used as a flame retardant additive in plastics, textiles, polyurethane foam, and other materials. PBDEs are generally added to products as three commercial mixtures (penta-BDE, octa-BDE, or deca-BDE mixtures), each of which contains different proportions of the 209 possible PBDE congeners that vary in their degree of bromination (Alaee et al., 2003). While the use of PBDEs in consumer products has helped reduce the loss of property and human life to fire, concerns have arisen recently about possible health risks associated with PBDE exposure. These concerns stem from accumulating evidence that levels of these persistent organic contaminants in the environment are rising (McDonald, 2002; Hites, 2004).

PBDEs can be transported by air and water to locations far from their source (Wania and Dugani, 2003), and PBDE contamination has now been documented in environments worldwide. This distribution includes even remote locations such as the deep ocean and the Arctic (De Boer et al., 1998; Ikonomou et al., 2002; Hale et al., 2003). PBDEs in the environment are bioavailable for uptake by organisms (Ciparis and Hale, 2005), and recent studies have established that PBDEs are present in the tissues of invertebrates, fish, birds, and marine mammals (Bayen et al., 2003; Fängström et al., 2005; Johnson-Restrepo et al., 2005; Domingo et al., 2006; Ikonomou et al., 2006; for review see Hites, 2004). PBDEs have even been detected in fishes and marine mammals that feed in offshore waters (De Boer et al., 1998; Ueno et al., 2004), indicating that these chemicals have become incorporated 
into pelagic and deep-sea food webs. PBDEs have also been found in the breast milk, blood and other tissues of humans (Schecter et al., 2003, 2005; Julander et al., 2005), signifying that the potential risks of PBDE contamination are not limited to wildlife. PBDEs are lipophilic, and congeners such as tetraBDE (PBDE 47) and penta-BDE (PBDE 99) can bioaccumulate rapidly in the lipid reservoirs of organisms. As a consequence, levels of these congeners can be considerably higher in body tissues than in the surrounding environment. Recent evidence has also shown that PBDEs can be converted metabolically from one congener to another or to hydroxylated forms not originally included in the commercial mixtures (Kierkegaard et al., 1999; Stapleton et al., 2004a,b; Tomy et al., 2004; He et al., 2006). With the heavy production and use of consumer products containing PBDEs, levels of PBDEs in wildlife and in humans in many parts of the world continue to rise (Ikonomou et al., 2002; Law et al., 2003; Rayne et al., 2003; Hites, 2004; Schecter et al., 2005; de Wit et al., 2006), elevating concerns about the potential ecological and human health risks associated with PBDE exposure (Darnerud et al., 2001; McDonald, 2002; Birnbaum and Staskal, 2004).

The present study explored the potential developmental toxicity of PBDEs using zebrafish (Danio rerio) as a model. The fundamental aspects of zebrafish development have been the focus of intensive research over the past decade. With this base of knowledge, zebrafish are proving increasingly useful for investigating mechanisms of chemical toxicity during early life stages (Hill et al., 2005; Hinton et al., 2005). Zebrafish embryos and larvae are mostly transparent, which allows for rapid and highthroughput screens for developmental abnormalities. Typically, zebrafish embryos are exposed to chemical contaminants, often at high concentrations, to induce clear phenotypic effects that point to physiological and molecular pathways of toxicity. This strategy has recently been used to identify novel mechanisms of toxicity in fish exposed to dioxins (Bello et al., 2004), polycyclic aromatic hydrocarbons (Incardona et al., 2005), current use pesticides (Haendel et al., 2004; Stehr et al., 2006) and heavy metals (Linbo et al., 2006). Here, we used a similar approach to investigate the developmental toxicity of $2,2^{\prime}, 4,4^{\prime}$-tetrabromodiphenyl ether (PBDE 47), commonly the most concentrated PBDE congener found in the tissues of wildlife and humans (Hale et al., 2001; Schecter et al., 2003; Brown et al., 2006; for review, see Hites, 2004). In fish, PBDEs may be transferred maternally in the lipid stores of oocytes, and offspring could be exposed to these compounds during the earliest stages of embryogenesis. However, potential mechanisms underlying the developmental toxicity of PBDE 47 are still poorly understood. The zebrafish experimental system allowed us to screen for adverse responses to a common PBDE congener that is an increasing concern for the early life stages of freshwater and marine fishes worldwide.

\section{Materials and methods}

\subsection{Animals}

Wild-type (AB strain) and nacre strain zebrafish were maintained in a breeding colony at the Northwest Fisheries Science
Center (Seattle, WA, USA) according to standard zebrafish breeding protocols (Westerfield, 1995). Adults were maintained at $26^{\circ} \mathrm{C}$ under a $14 \mathrm{~L}: 10 \mathrm{D}$ photoperiod in a closed flow-through system. Water supplied to the system was filtered by reverse osmosis (pH 7.5-8), and Instant Ocean ${ }^{\circledR}$ salt was added to the water to raise the conductivity to $\sim 1500 \mu \mathrm{S} / \mathrm{cm}$ (system water). Zebrafish embryos were obtained by spawning adults in groups containing three females and two males overnight in spawning tanks. Eggs were collected and rinsed briefly with system water. Fertilized eggs were then staged under a stereomicroscope according to the descriptions of Kimmel et al. (1995).

\subsection{PBDE treatments}

We obtained 2,2',4,4'-tetrabromodiphenyl ether (PBDE 47, purity $>99 \%$ ) from ChemService, Inc. (West Chester, PA, USA). A stock solution of PBDE 47 was prepared by dissolving $0.0165 \mathrm{~g}$ of PBDE $47 \mathrm{in} 10 \mathrm{ml}$ of dimethyl sulfoxide (DMSO, Sigma). This stock solution was then diluted in system water to create a graded series of PBDE 47 solutions. Larval zebrafish were exposed to PBDE 47 at concentrations calculated from 100 to $5000 \mu \mathrm{g} / \mathrm{l}$ in system water with $0.3 \%$ DMSO. The control exposure consisted of system water containing $0.3 \%$ DMSO only.

Zebrafish embryos were $3-5 \mathrm{~h}$ post-fertilization (hpf) of age when assigned to experimental treatments, and were exposed to PBDE 47 or control treatments until $168 \mathrm{hpf}$. For all experiments, embryos and larvae were maintained at $28.5^{\circ} \mathrm{C}$ and reared in sterile 24 well plates (Corning International, Corning, NY, USA) at a density of four fish per $3 \mathrm{ml}$ well. Treatment solutions were changed in the wells every $48 \mathrm{~h}$.

\subsection{Quantification of PBDE 47 in larval tissues}

We used gas chromatography with electron capture detection (GC-ECD) to determine the concentration of PBDE 47 present in whole-body tissues of larval zebrafish from the aqueous treatments described above. From 3 to 5 hpf of age, larval zebrafish were reared in system water containing PBDE $47(100,500$, or $5000 \mu \mathrm{g} / \mathrm{l}$ ) or control water (system water with $0.3 \%$ DMSO) in 24 well plates with four larvae per $3 \mathrm{ml}$ well. Water was changed in all wells at $48 \mathrm{hpf}$. When larvae reached $96 \mathrm{hpf}$, they were euthanized in MS222 dissolved in system water $(250 \mu \mathrm{g} / \mathrm{ml}$, tricaine methanesulfonate; Argent Chemical Laboratories, Redmond, WA) and then rinsed briefly in clean system water. Larvae were then weighed in groups of $\sim 30$ individuals (range, 22-37 individuals) so that the total tissue mass of each sample was $6.6 \pm 0.4 \mathrm{mg}$ (mean \pm S.E.). These samples $(n=4$ groups of larvae per treatment) were then frozen immediately in liquid nitrogen and stored at $-80^{\circ} \mathrm{C}$.

To quantify tissue levels of PBDE 47, the pooled zebrafish larvae were homogenized in deionized water and spiked with $20 \mu \mathrm{l}$ of a $240 \mathrm{ng} / \mathrm{ml}$ solution of polycholorinated biphenyl 103 (PCB 103, w/v in hexane; purchased from Sigma-Aldrich, St. Louis MO) as an internal standard. Hexane $(1 \mathrm{ml})$ was then added, and the homogenate was vortexed for $30 \mathrm{~s}$ and centrifuged at $3000 \times g$ for $5 \mathrm{~min}$. The hexane layer was transferred to a 
GC-ECD autosampler vial and diluted 1:10 with hexane. The extraction efficiency of PBDE 47 was typically 90-95\%. The hexane extracts were then analyzed on a Hewlett-Packard 5890 GC equipped with a DB-5 30-m, $0.25 \mu \mathrm{M}$ capillary column. The GC was operated in split injection mode with a split ratio of 8:1. The specific chromatographic conditions were as follows: injection port temperature of $250{ }^{\circ} \mathrm{C}$; detector temperature of $300{ }^{\circ} \mathrm{C}$; initial oven temperature of $90{ }^{\circ} \mathrm{C}$ and then raised to $250^{\circ} \mathrm{C}$ at $20^{\circ} \mathrm{C} / \mathrm{min}$, then raised to $280^{\circ} \mathrm{C}$ at $5^{\circ} \mathrm{C} / \mathrm{min}$ and held for three additional minutes. Under these separation conditions, the retention time of PBDE 47 was 12.16 min and PCB 103 was $8.75 \mathrm{~min}$. Standard curves prepared for PBDE 47 ranged from concentrations of 0 to $1.51 \mu \mathrm{g}$.

\subsection{Effects of PBDE 47 on hatching, morphological development, and survival}

To determine whether exposure to PBDE 47 affected the timing of hatching for zebrafish, we recorded the percentage of embryos that emerged from the chorion in each treatment well at 48,56 , and $72 \mathrm{hpf}$. Hatching rates were calculated as the percentage of embryos that had hatched per plate well (with four embryos per well). Wells were replicated 24 times for each exposure treatment to give final sample sizes of $n=24$ replicate wells per treatment. At $30 \mathrm{hpf}$, the rate of spontaneous movements by the embryo in the chorion was observed under a stereomicroscope (Nikon SMZ800) and recorded $(n=20$ replicates per treatment). These behavioral observations were blind so that the observer did not have knowledge of the treatment.

Throughout development, embryos and larvae were examined under a stereomicroscope to screen for morphological abnormalities and record survival rates within each treatment. The timing of formation of specific embryonic structures was compared to an established atlas for normal zebrafish development (Westerfield, 1995). Fish were monitored daily from 24 to $168 \mathrm{hpf}$. Sample sizes were $n=40$ replicate rearing wells per treatment, with replicates for each treatment equally balanced across 24 well plates.

At two points during development (72 and $96 \mathrm{~h}$ postfertilization), body length of the larval fish was measured to determine whether PBDE 47 exposure altered growth. Zebrafish were anesthetized in MS222 and photographed with a digital camera (Spot RT camera with Spot 3.2.6 imaging software, Diagnostic Instruments, Inc., Sterling Heights, MI) attached to a stereomicroscope (Nikon SMZ800). The length of each fish along the body axis from the rostrum to the base of the tail was measured from these digital images using ImageJ software (version 1.33, National Institutes of Health, USA). Values for body length are presented as mean body length per well. Sample sizes were $n=24$ replicate wells per treatment.

\subsection{Effects of PBDE 47 on cardiac function}

We quantified cardiac beat rate to determine whether exposure to PBDE 47 affected cardiac function in larval zebrafish. Larvae were exposed to PBDE 47 at 0,500 , or $5000 \mu \mathrm{g} / \mathrm{l}$ beginning at $3 \mathrm{hpf}$. When fish reached $72 \mathrm{hpf}$, a subset of the larvae were lightly anesthetized in MS222 $(250 \mu \mathrm{g} / \mathrm{ml})$ and mounted in $3 \%$ methyl cellulose (Sigma, St. Louis, MO, USA) on glass slides. Videos of the heart were recorded via a digital camera (Fire i400, Unibrain, San Ramon, CA, USA) attached to a brightfield Nikon E600 compound microscope. Beat rates for both the atrium and ventricle were later quantified from these digital videos by a blind observer using BTV Pro Carbon 5.4.1 software. Sample sizes were $n=10-11$ fish for all treatments and developmental ages except for the highest dose of PBDE 47 $(5000 \mu \mathrm{g} / \mathrm{l})$ at $168 \mathrm{hpf}$. Larvae in the $5000 \mu \mathrm{g} / \mathrm{l}$ PBDE 47 treatment experienced high mortality by this age (see Section 3 ), so only the few surviving fish $(n=2)$ could be sampled.

\subsection{Imaging of cerebrospinal fluid flow in the neural tube and brain ventricles}

We spawned adult zebrafish of the reduced-pigment nacre strain following the protocol described above, and reared the embryos in $5000 \mu \mathrm{g} / \mathrm{l}$ PBDE $47(n=15)$ or $0.3 \%$ DMSO control $(n=14)$ solutions in 24 well plates with four fish per well. At $144 \mathrm{hpf}$, the larvae were lightly anesthetized in MS222 $(250 \mu \mathrm{g} / \mathrm{ml})$ and mounted in $2 \%$ low melt agarose (LMP UltraPure agarose, Invitrogen Corp., Carlsbad, CA, USA). The hindbrain ventricle was microinjected dorsally with a 5\% solution of dextran dye containing tetramethylrhodamine $(70,000$ MW; Molecular Probes, Inc., Eugene, OR, USA) according to methods described by Lowery and Sive (2005). The fluorescent dye was allowed to distribute throughout the brain ventricles and down the neural tube for $20 \mathrm{~min}$, at which time we quantified the distance down the neural tube that the dye had traveled. This distance was measured by counting the number of segmented skeletal muscle myotomes passed by the fluorescent dye in the neural tube. At this time, we also captured lateral fluorescent photomicrographs of the brain using a digital camera (Fire i400, Unibrain, San Ramon, CA) mounted on a Nikon E600 microscope to document the dispersion of dye from the hindbrain ventricle forward into the forebrain and midbrain ventricles. Larvae were then quickly fixed in $4 \%$ paraformaldehyde, rinsed in phosphate buffered saline $(0.1 \mathrm{M})$, and imaged dorsally using a confocal laser-scanning microscope (LSM 5 Pascal, Carl Zeiss, Inc., Oberkochen, Germany).

\subsection{Effects of early pulse exposures to PBDE 47}

To test whether transient exposure to PBDE 47 during early embryogenesis is sufficient to cause developmental disorders, zebrafish embryos were exposed to PBDE 47 for a $20 \mathrm{~h}$ interval beginning at $3 \mathrm{hpf}$. Embryos were exposed to aqueous solutions of PBDE 47 at 100, 500, or $5000 \mu \mathrm{g} / \mathrm{l}$ or a vehicle control solution $(0.3 \%$ DMSO) in 24 well plates. After $20 \mathrm{~h}$ of exposure, embryos from all treatments were removed from the PBDE 47 and control solutions, rinsed in system water for 1 min over a plastic screen, and transferred to clean system water in new 24 well plates. The clean water was then changed every $48 \mathrm{~h}$ in each well. At $168 \mathrm{hpf}$, larvae from all treatments were screened for developmental abnormalities. Sample sizes were $n=15$ wells per treatment. 


\subsection{Statistical analyses}

Since the hatching data failed to conform to the assumptions of normality, we used a Kruskal-Wallis nonparametric test to examine whether PBDE 47 affected the percentage of fish that had hatched from the chorion at 48, 56, and $72 \mathrm{hpf}$. We then used a Dunnett's test to conduct pairwise comparisons between PBDE 47 treatments and the control (Zar, 1999). The body length of larvae at 72 and $96 \mathrm{hpf}$ was compared among treatments using one-factor analysis of variance (ANOVA) models, followed by Dunnett's tests for multiple pairwise comparisons with the control. We used repeated-measures multiple analysis of variance (MANOVA) models to determine whether PBDE 47 affected the incidence of morphological deformities, survivorship, and the beat rate of the atrium and ventricle heart chambers. We tested for interactions between treatment and time in these MANOVA models using the Wilks' lambda $(\Lambda)$ test statistic. Within each time point, pairwise comparisons between each treatment and the control were made using Dunnett's tests. The flow rate of fluorescent dextran dye down the neural tube was compared between PBDE 47 and control treatments using a twosample $t$ test. Lastly, we used a Kruskal-Wallis nonparametric test to examine whether short-term $(20 \mathrm{~h})$ exposure to PBDE 47 affected the frequency of morphological abnormalities, followed by a Dunnett's test to conduct pairwise comparisons between the control groups and the PBDE 47 treatments. All statistical tests were two-tailed and performed using JMP 5.1 software (SAS Institute, Inc.).

\section{Results}

\subsection{Whole-body tissue levels of PBDE 47}

Levels of PBDE 47 in whole-body tissue homogenates of larvae (96 hpf of age) exposed to control solution and to PBDE 47 at 100,500 , and $5000 \mu \mathrm{g} / \mathrm{l}$ are provided in Table 1 . Tissue concentrations of PBDE 47 varied among treatments as expected by the graded concentrations of PBDE 47 solutions.

\subsection{Exposure to PBDE 47 delays hatching and impairs growth}

Embryos exposed to PBDE 47 at concentrations of 2000 and $5000 \mu \mathrm{g} / \mathrm{l}$ hatched later from the chorion than embryos exposed to the control $0.3 \%$ DMSO solution. This delay in hatching was significant at $56 \mathrm{hpf}$ (Table 2) but appeared to be short in dura-

Table 1

Concentrations of PBDE 47 in whole-body tissues of zebrafish (at $96 \mathrm{~h}$ postfertilization) from static-renewal exposures

\begin{tabular}{lcl}
\hline Treatment & \multicolumn{2}{l}{ Tissue concentration } \\
\cline { 2 - 3 } & $(\mu \mathrm{g}$ PBDE 47 per g wet wt) & $(\mu \mathrm{g}$ PBDE 47 per fish) \\
\hline Control & $0.00 \pm 0.00$ & $0.000 \pm 0.000$ \\
$100 \mu \mathrm{g} / 1$ & $3.36 \pm 0.72$ & $0.001 \pm 0.000$ \\
$500 \mu \mathrm{g} / 1$ & $77.54 \pm 7.82$ & $0.016 \pm 0.002$ \\
$5000 \mu \mathrm{g} / 1$ & $293.28 \pm 21.64$ & $0.060 \pm 0.005$ \\
\hline
\end{tabular}

Table 2

Effects of PBDE 47 on mean ( \pm S.E.) percent of embryos hatched at 48, 56, and $72 \mathrm{~h}$ post-fertilization (hpf)

\begin{tabular}{llll}
\hline PBDE 47 dose & \multicolumn{3}{l}{$\%$ embryos hatched } \\
\cline { 2 - 4 } & $48 \mathrm{hpf}$ & $56 \mathrm{hpf}$ & $72 \mathrm{hpf}$ \\
\hline Control & $4.2 \pm 2.3$ & $67.7 \pm 4.9$ & $96.9 \pm 1.7$ \\
$100 \mu \mathrm{g} / 1$ & $2.1 \pm 1.4$ & $61.5 \pm 5.2$ & $96.9 \pm 1.7$ \\
$500 \mu \mathrm{g} / 1$ & $3.1 \pm 1.7$ & $51.0 \pm 6.1$ & $94.8 \pm 2.1$ \\
$1000 \mu \mathrm{g} / 1$ & $4.2 \pm 2.5$ & $49.0 \pm 7.1$ & $96.9 \pm 1.7$ \\
$2000 \mu \mathrm{g} / 1$ & $6.3 \pm 3.8$ & $34.4 \pm 6.5^{*}$ & $93.8 \pm 2.7$ \\
$5000 \mu \mathrm{g} / 1$ & $0.0 \pm 0.0$ & $43.7 \pm 4.9^{*}$ & $97.9 \pm 1.4$ \\
& $\chi^{2}=3.5140$, & $\chi^{2}=17.8787$, & $\chi^{2}=2.6041$, \\
& $p=0.6213$ & $p=0.0031$ & $p=0.7607$ \\
\hline
\end{tabular}

Note: Asterisks indicate significant difference from control (Dunnett's test, $p<0.05)$.

tion, as we found no effect of PBDE 47 on the proportion of fish hatched at either $48 \mathrm{hpf}$ or $72 \mathrm{hpf}$. This temporary delay in hatching was not associated with any significant developmental delay of embryogenesis as fish exposed to PBDE 47 followed normal developmental timing as described by Kimmel et al. (1995). Moreover, the delayed hatching seen in PBDE 47exposed larvae did not appear to be caused by differences in
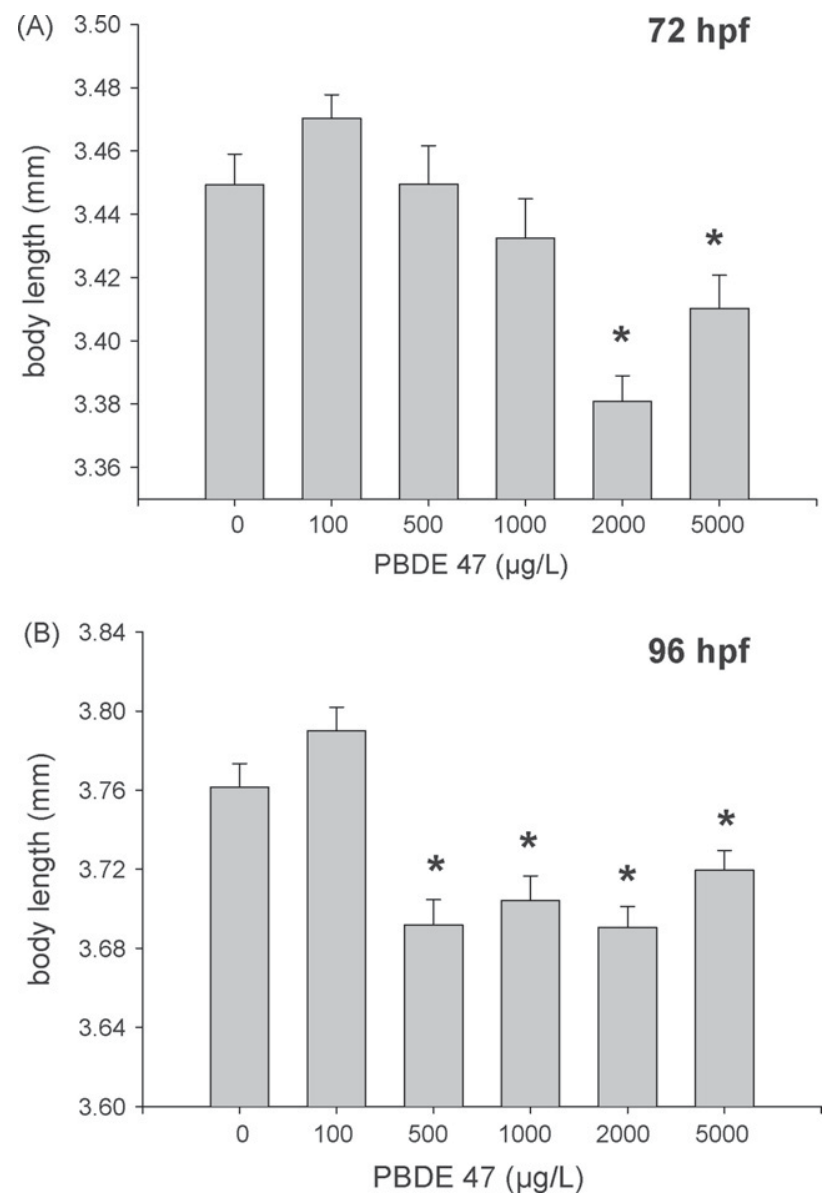

Fig. 1. Exposure to PBDE 47 resulted in larvae with a smaller body length at $72 \mathrm{~h}$ post-fertilization (hpf) (A) and $96 \mathrm{hpf}$ (B). Asterisks indicate significant difference from control. Values are presented as mean \pm S.E. 
the activity of embryos within the egg, since embryos exposed to PBDE 47 at 500 and $5000 \mu \mathrm{g} / \mathrm{l}$ showed no difference in the frequency of spontaneous movements within the chorion compared to control embryos (control, $0.59 \pm 0.11$ movements per min; $500 \mu \mathrm{g} / 1$ PBDE 47, $0.81 \pm 0.12 ; 5000 \mu \mathrm{g} / 1$ PBDE 47, $0.88 \pm 0.13: F_{2,55}=1.6147, p=0.2082$ ).

Zebrafish treated with PBDE 47, however, were smaller in body length shortly after hatching (Fig. 1). At $72 \mathrm{hpf}$, this reduction in body length was statistically significant only in larvae exposed to PBDE 47 at exposures that also delayed hatching at $56 \mathrm{hpf}$ (see Table 2). By $96 \mathrm{hpf}$, however, larvae exposed to lower concentrations of PBDE $47(500 \mu \mathrm{g} / \mathrm{l}$ and greater) were also smaller in body size compared to controls.

\subsection{PBDE 47 causes developmental defects and larval mortality}

Larvae exposed to PBDE 47 showed a consistent and highly repeatable suite of morphological deformations. These abnormalities included the development of an abnormal dorsal curvature of the trunk and tail which first appeared at $72 \mathrm{hpf}$ at the highest exposure concentration and became more pronounced over the next few days of larval development (Fig. 2). This trunk curvature occurred in $\sim 100 \%$ of the larvae exposed to PBDE 47 at aqueous solutions of $400 \mu \mathrm{g} / \mathrm{l}$ or greater (Fig. 3). However, the temporal onset of this abnormality was dose-dependent, with trunk malformation appearing
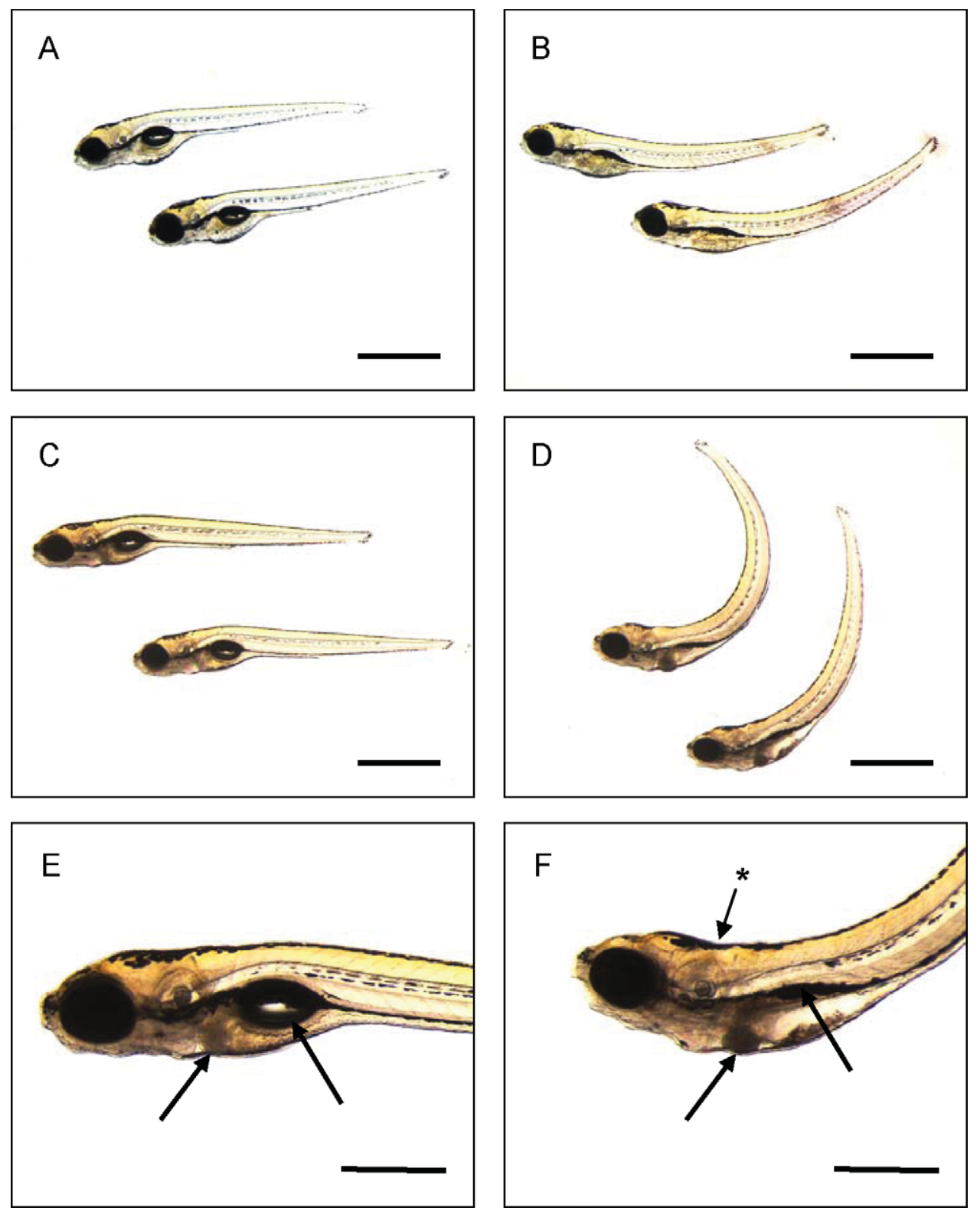

Fig. 2. Exposure to PBDE $47(5000 \mu \mathrm{g} / \mathrm{l})$ caused morphological abnormalities including the development of a dorsally curved tail and the failed inflation of the swim bladder. Lateral view of control (A) and PBDE 47-exposed (B) larvae at $96 \mathrm{~h}$ post-fertilization (hpf). Lateral view of control (C and E) and PBDE 47-exposed (D and F) larvae at $164 \mathrm{hpf}$. Higher magnification views in $\mathrm{E}$ and $\mathrm{F}$ show the failed inflation of the swim bladder and an unusually dark liver (arrows) and a flexion at the hindbrain (asterisk) in PBDE 47-exposed fish. Scale bars $=1 \mathrm{~mm}(\mathrm{~A}-\mathrm{D})$ and $500 \mu \mathrm{m}$ (E and F). 


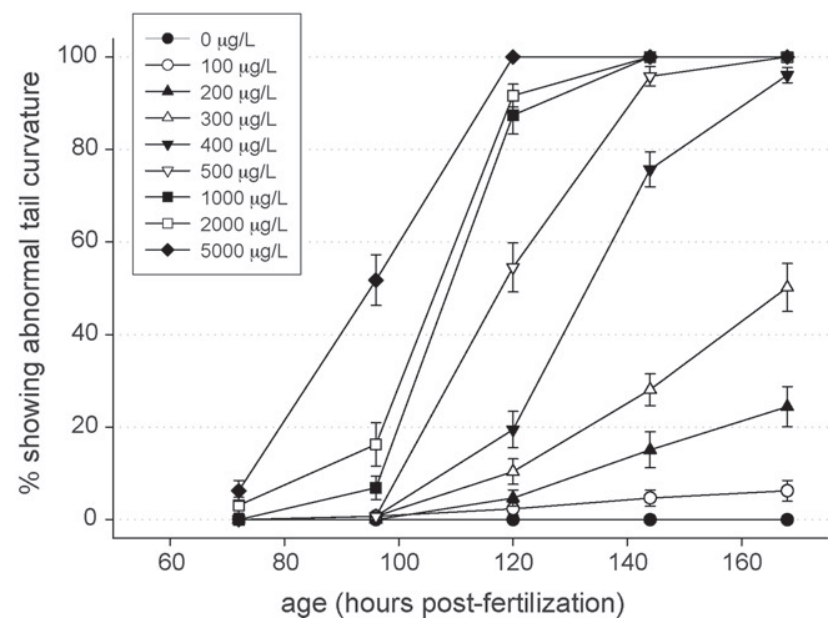

Fig. 3. The frequency of abnormal dorsal tail curvature plotted against larval age in hours post-fertilization (hpf). The occurrence of this dorsal tail curvature was dose-dependent (treatment effect, $F_{8,275}=13.3271, p<0.0001$ ). All exposures began at 3-5 hpf and were renewed every $48 \mathrm{~h}$ until larvae were $172 \mathrm{hpf}$ of age. Values are presented as mean \pm S.E.

later for fish exposed to PBDE 47 at the lower concentrations (treatment effect, $F_{8,275}=13.3271, p<0.0001$; time effect, $F_{4,272}=21.8288, p<0.0001$; treatment $\times$ time interaction, Wilks' $\left.\Lambda, F_{32,1005}=62.0006, p<0.0001\right)$. We did not, however, observe any corresponding edema of the eyes or pericardial cavity in larvae exhibiting this tail curvature, as has been observed in several recent studies of toxicant-induced body axis defects in zebrafish larvae (i.e., Blechinger et al., 2002; Incardona et al., 2004; Lefebvre et al., 2004).

At the upper range of PBDE 47 exposures (400-5000 $\mu \mathrm{g} / \mathrm{l})$, dorsal tail curvature was often accompanied by additional developmental abnormalities. These changes included a failure of the swim bladder to inflate, a discoloration of the liver, and a flexion of the head at the level of the hindbrain (Fig. 2E and F). After the development of trunk curvature, larvae swam in an abnormal swirling motion. However, prior to the appearance of the dorsal trunk curvature, larvae showed unusually lethargic movement suggesting that there may be more subtle physiological effects of PBDE 47 exposure exhibited prior to the acute morphological effects documented here. Exposure to PBDE 47 at $500 \mu \mathrm{g} / \mathrm{l}$ or higher significantly reduced larval survival by $168 \mathrm{hpf}$ relative to controls (Fig. 4). Survival was influenced by the dose of PBDE 47, with mortality occurring earlier in larvae exposed to higher PBDE 47 levels (treatment effect, $F_{8,315}=26.5841, p<0.0001$; time effect, $F_{6,310}=156.5638, p<0.0001$, treatment $\times$ time interaction, Wilks' $\left.\Lambda, F_{48,1529}=15.4581, p<0.0001\right)$.

\subsection{Exposure to PBDE 47 alters cardiac function}

Exposures to PBDE 47 at 500 and $5000 \mu \mathrm{g} / 1$ had disruptive effects on cardiac function in larval zebrafish. These effects included a significant increase in the beat rates (tachycardia) of both the atrium (treatment effect, $F_{2,19}=1.6141, p=0.2252$; time effect, $F_{4,16}=9.1732, p=0.0005$; treatment $\times$ time inter-

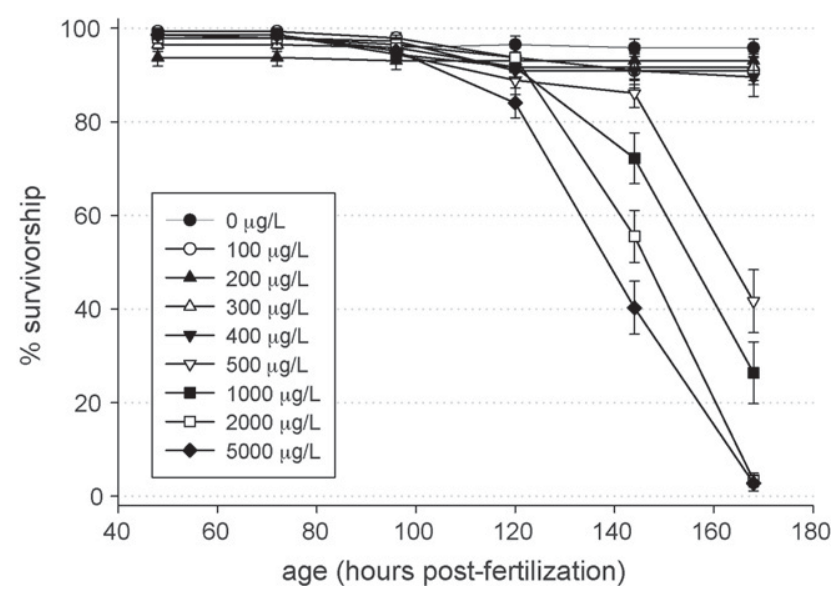

Fig. 4. Exposure to PBDE 47 decreased survival. The percent survivorship of larvae exposed to PBDE 47 was highly dose-dependent (treatment effect, $\left.F_{8,315}=26.5841, p<0.0001\right)$. All PBDE 47 exposures began at $3-5 \mathrm{~h}$ postfertilization (hpf) and were renewed every $48 \mathrm{~h}$. Values are presented as mean \pm S.E.

action, Wilks' $\left.\Lambda, F_{8,32}=2.6213, p=0.0249\right)$ and ventricle (treatment effect, $F_{2,19}=2.3504, p=0.1224$; time effect, $F_{4,16}=8.6640, p=0.0006$; treatment $\times$ time interaction, Wilks' $\Lambda, F_{8,32}=5.1803, p=0.0003$ ) (Fig. 5A). Tachycardia first appeared when larvae were between 72 and $96 \mathrm{hpf}$ of age and its extent was positively related to PBDE dose. Moreover, at the higher PBDE 47 exposure concentration $(5000 \mu \mathrm{g} / \mathrm{l})$, tachycardia progressed into arrhythmia by $120 \mathrm{hpf}$, as indicated by a deviation in the atrium to ventricle beat ratio (Fig. 5B; treatment effect, $F_{2,19}=20.9454, p<0.0001$; time effect, $F_{4,16}=12.1178, p<0.0001$; treatment $\times$ time interaction, Wilks' $\left.\Lambda, F_{8,32}=5.5340, p=0.0002\right)$. The observed arrhythmias were typically regular and represented various degrees of atrioventricular conduction block, i.e., atrial:ventricular beat ratios of $4: 1,5: 1$ and $8: 1$.

\subsection{PBDE 47 alters cerebrospinal fluid movement in the neural tube and brain}

Live examination of PBDE 47-exposed larvae suggested subtle alterations in circulation of blood within the hindbrain. To explore the potential link between CNS hemodynamics, cerebrospinal fluid (CSF) dynamics, and dorsal curvature, we assessed CSF movement after microinjection of fluorescent dextran dye into the hindbrain ventricle (Fig. 6A). Movement of $\mathrm{CSF}$ in the brain ventricles and central canal of the neural tube was reduced in larvae exposed to PBDE $47(5000 \mu \mathrm{g} / \mathrm{l})$. Dye in the CSF traveled significantly slower down the central canal in PBDE-exposed larvae compared to control fish (Fig. 6B; $t=4.4687, p<0.0001$ ). Movement of the dye from the hindbrain forward into the midbrain and forebrain ventricles was also reduced in PBDE 47 treated fish. At 20 min after injection, the dye had dispersed forward into the forebrain ventricle in only 27\% (4 of 15) of PBDE 47 larvae compared to $79 \%$ (11 of 14 ) of the controls. Taken together, these findings suggest that PBDE 47 exposure caused significant 

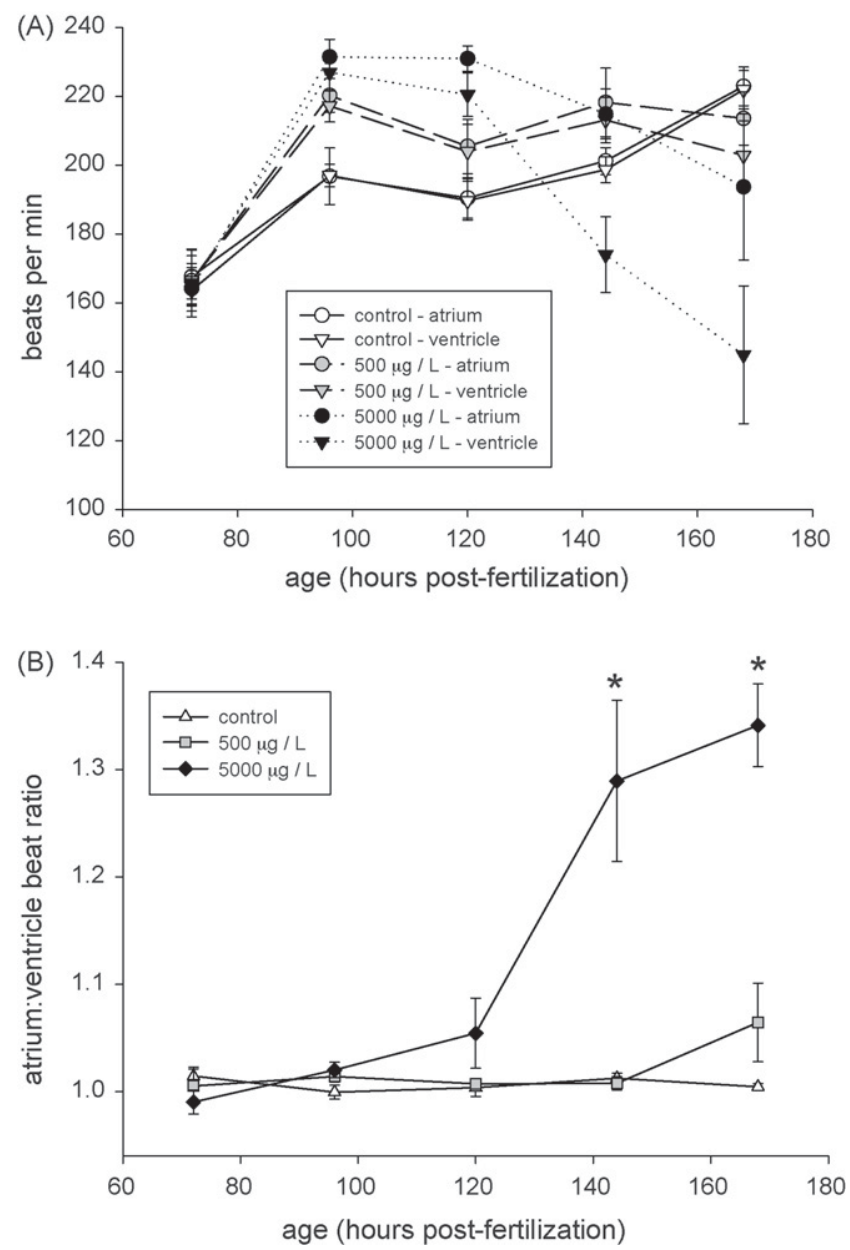

Fig. 5. PBDE 47 elevated heart rate and induced a cardiac arrhythmia in zebrafish larvae. (A) The atrial and ventricular rates were significantly higher at $96 \mathrm{~h}$ postfertilization (hpf) in larvae exposed to PBDE 47. This elevated cardiac rate developed between 72 and $96 \mathrm{hpf}$. (B) The atrium:ventricle beat ratio plotted against larva age (hpf). Zebrafish larvae exposed to PBDE 47 at concentrations of $5000 \mu \mathrm{g} / \mathrm{l}$ developed a cardiac arrhythmia by $144 \mathrm{hpf}$. Asterisks indicate a statistically significant difference from control (Dunnett's tests, $p<0.05$ ). All PBDE 47 exposures began at 3-5 hpf and were renewed every $48 \mathrm{~h}$, and values are presented as mean \pm S.E.

changes in CSF dynamics within the brain ventricles and neural tube.

\subsection{Transient embryonic exposure to PBDE 47 causes subsequent toxicity}

Exposure to PBDE 47 during early embryogenesis (3-23 hpf) caused morphological abnormalities similar to those seen in larvae exposed continuously to PBDE $47\left(\chi_{0.05 .5}^{2}=49.3188\right.$, $p<0.0001$ ) (Fig. 7A). The proportion of fish showing these abnormalities, however, was considerably reduced with only a $20 \mathrm{~h}$ period of PBDE 47 exposure compared to static-renewal exposures. Larvae treated with PBDE 47 (at concentrations of 500 and $5000 \mu \mathrm{g} / \mathrm{l})$ for $20 \mathrm{~h}$ still developed an abnormal dorsally curved tail by $7 \mathrm{dpf}$, however this spinal curvature was less pronounced in even the most severely curved individuals from the $20 \mathrm{~h}$ exposure (Fig. 7B) compared to larvae from the contin- uous static-renewal PBDE 47 exposures (see Fig. 3D). Larvae exposed to PBDE 47 for only $20 \mathrm{~h}$ also showed normal swim bladder inflation.

\section{Discussion}

Our results demonstrate that exposure to PBDE 47 during early life can cause developmental changes in fish including reduced growth, abnormal morphology, irregular cardiac function, and altered cerebrospinal fluid flow. These PBDE-induced changes were manifested early in development, with the first effects of PBDE 47 exposure seen as a delay in hatching and a reduction in body size. Shortly after hatching, however, larvae exposed to PBDE 47 began to exhibit a consistent and repeatable suite of morphological abnormalities that included the development of an abnormal dorsally curved tail. This tail curvature was first seen at an age of $72 \mathrm{hpf}$ in fish exposed to the highest doses of PBDE 47, and became more pronounced and common over the next several days in larvae exposed to all PBDE 47 doses. PBDE 47 also induced cardiac abnormalities and changes in cerebrospinal fluid movement in zebrafish larvae. Cardiac changes were first seen as tachycardia by $96 \mathrm{hpf}$, but progressed into atrioventricular block arrhythmias that may have contributed to the high mortality seen in fish exposed to the highest concentrations of PBDE 47. We also observed that larvae exposed to PBDE 47 showed reduced movement of cerebrospinal fluid in the brain ventricles and neural tube. Movement of cerebral spinal fluid plays a key role in regulating stem cell proliferation and normal brain development (Owen-Lynch et al., 2003; Miyan et al., 2003), and reductions in cerebrospinal fluid flow have been linked to depressed neurogenesis and mental retardation in rodents (Mashayekhi et al., 2002). Changes in cerebral spinal fluid flow in zebrafish exposed to PBDE 47 may thus lead to the development of neural deficiencies later in life.

The toxic developmental effects of PBDE 47 were clearly dose-dependent, with higher doses of dissolved PBDE 47 manifesting abnormalities earlier in development. While we primarily reared embryos and larvae in static-renewal exposures to PBDE 47, we also found that similar, though less pronounced, morphological abnormalities were manifest in zebrafish larvae exposed to PBDE 47 for only a $20 \mathrm{~h}$ period during early life (when larvae were 3-23 hpf of age). Even though the embryos were reared in clean water for all but the first $20 \mathrm{~h}$ of development, these fish still displayed toxicological effects of PBDE 47 exposure. PBDEs are highly lipophilic, and PBDE 47 may have been incorporated into lipid stores of the embryo during the $20 \mathrm{~h}$ embryonic exposure. Incorporated PBDE 47 may then have been bioavailable to induce toxicological effects later in development. Further support for this idea comes from our preliminary observations that zebrafish embryos exposed to PBDE 47 during other periods of development (24-48 or 48-72 hpf) also developed a dorsal tail curvature by $168 \mathrm{hpf}$ (data not shown). In fish and other taxa, the egg can be a significant pathway for embryonic exposure to PBDEs (Petersen and Kristensen, 1998). Our results showing that a brief exposure to PBDE 47 during embryogenesis can cause morphological abnormalities suggest that PBDEs 
A
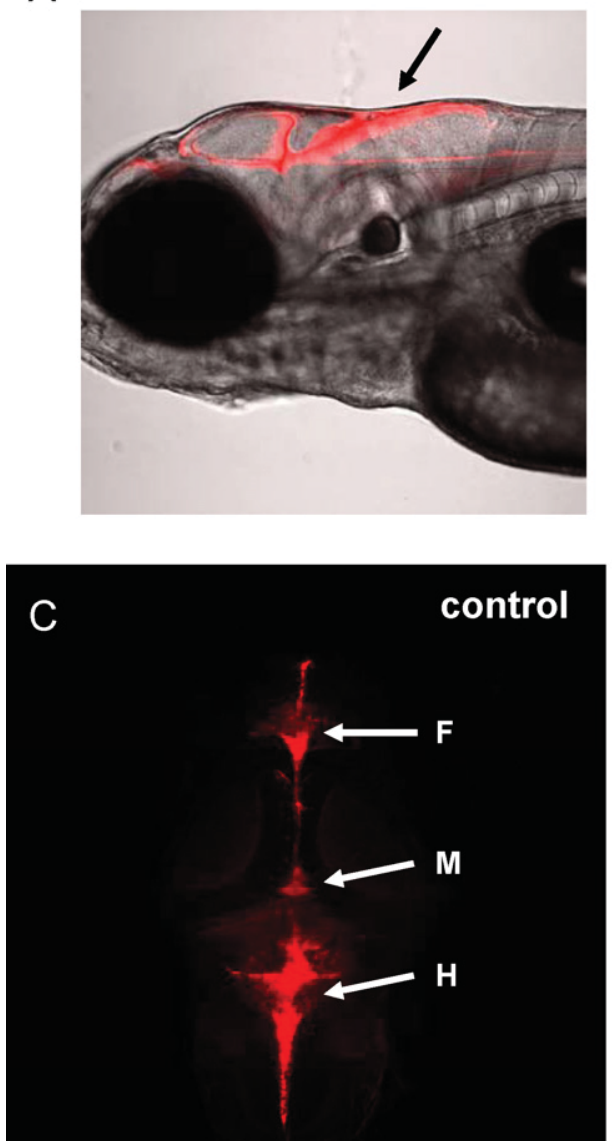

B
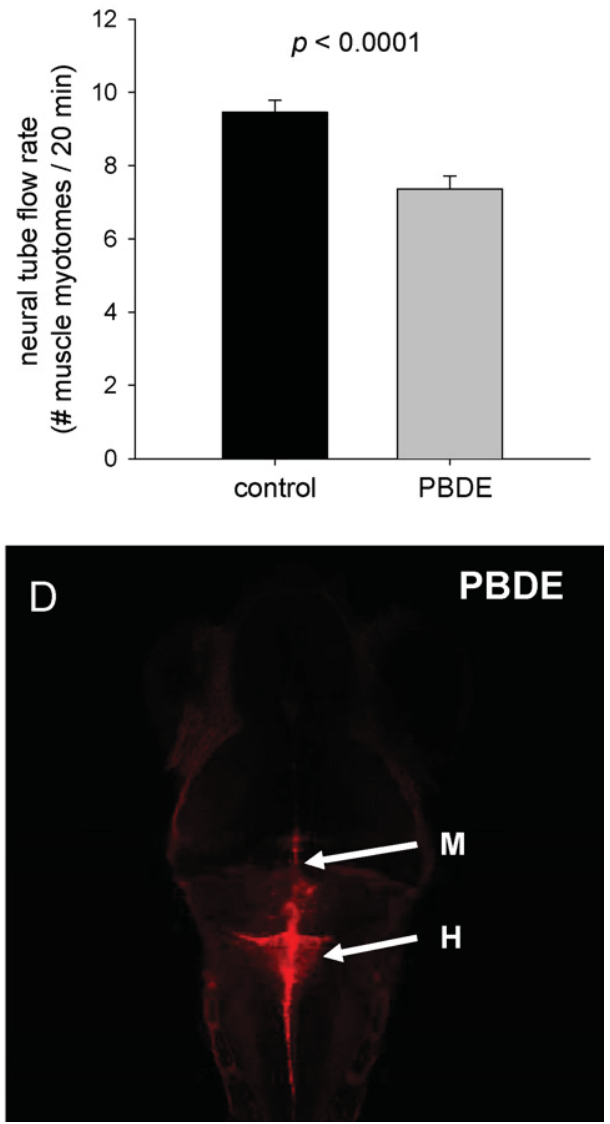

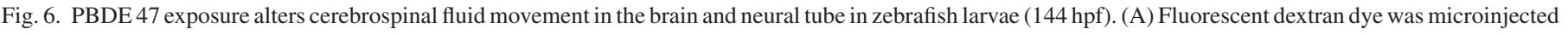

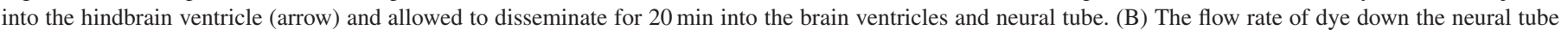

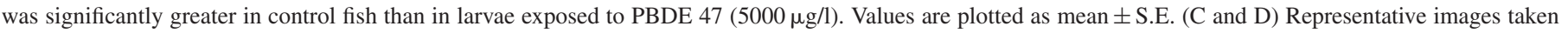

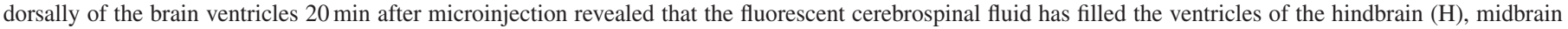
(M), and forebrain (F) in control larvae (C), but had not yet reached the forebrain ventricle in PBDE 47-exposed larvae (D).

transferred maternally through the oocyte might result in developmental toxicity in fish during later life.

\subsection{Biological impacts and mechanisms of PBDE toxicity}

PBDEs are an emerging organic pollutant (Hale et al., 2001; McDonald, 2002; Birnbaum and Staskal, 2004), yet much remains unknown about the biological effects of PBDE exposure. Studies from controlled PBDE exposures in the laboratory have shown that PBDEs can impact neural function and behavior. Neonatal exposure to each of the PBDE congeners PBDE 47, PBDE 99, PBDE 153, and PBDE 209 has been shown to cause long-term behavioral abnormalities including elevated spontaneous behaviors and learning/memory deficiencies in rodents (Eriksson et al., 2002; Viberg et al., 2003a, 2004; Branchi et al., 2005; Lilienthal et al., 2005). In fish, exposure to the commercial PBDE mixture DE-71 caused delayed hatching and alterations in behavior that included depressed swimming activity and feeding rates in larval mummichog, Fundulus heteroclitus (TimmeLaragy et al., 2006). While behavioral changes in mummichog were observed at DE-71 concentrations as low as $0.001 \mu \mathrm{g} / \mathrm{l}$, a delay in hatching was only seen at the highest DE-71 concen- tration tested $(100 \mu \mathrm{g} / \mathrm{l})$. Although the mechanisms underlying these defects are unclear, as are the precise cellular or molecular targets of PBDEs, recent studies have focused on thyroid hormone function and cholinergic pathways in the CNS. PBDEs depressed plasma levels of the thyroid hormone thyroxine $\left(\mathrm{T}_{4}\right)$ in a variety of vertebrates including rodents (Hallgren et al., 2001; Hallgren and Darnerud, 2002), birds (Fernie et al., 2005), and fish (Tomy et al., 2004). In rodents, PBDE exposure has also been shown to alter cholinergic functioning in neural tissues (Dufault et al., 2005). Rats exposed to PBDEs had fewer nicotinic acetylcholine receptors in the hippocampus, possibly contributing to impaired learning and memory (Viberg et al., 2002, 2003b, 2005).

Are there potential links between these neurotoxic or endocrine-disrupting effects of PBDEs and our observed effects of PBDE 47 during zebrafish development? Overall, two lines of evidence suggest that the most pronounced effects of PBDE 47 described here arise from impacts on neural development. First, dorsal curvature of the body axis can be secondary to defects in cardiac function (Incardona et al., 2004, 2006), most likely due to the links between systemic blood pressure, CSF secretion, and maintenance of brain ventricle volume (Carey and Vela, 1974; 


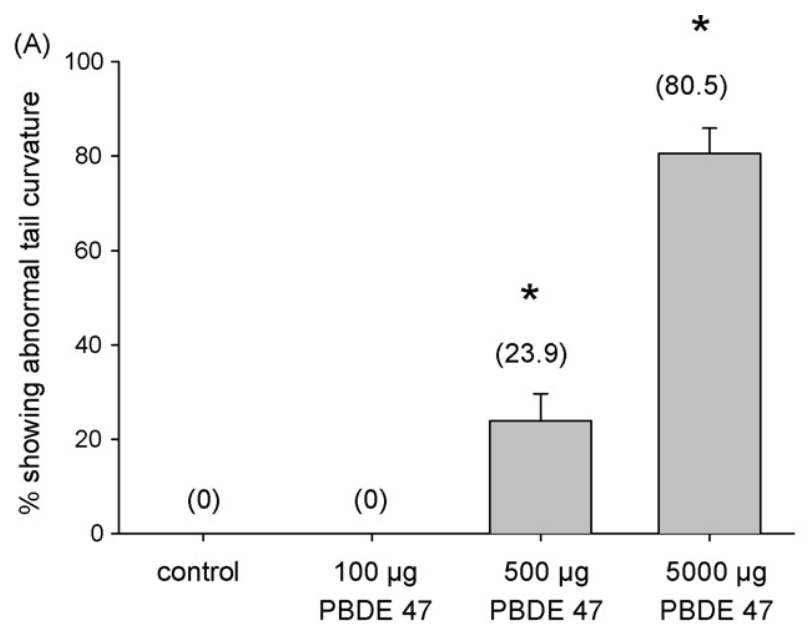

(B)

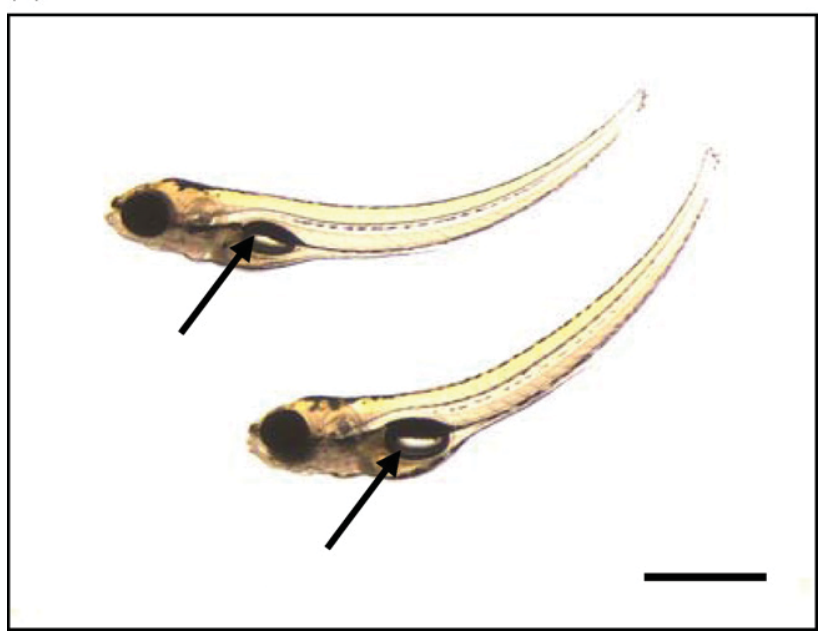

Fig. 7. Developmental toxicity of PBDE 47 in zebrafish exposed for only a $20 \mathrm{~h}$ period during early embryogenesis $(3-23 \mathrm{hpf})$. (A) The percent of larvae showing morphological abnormalities at $168 \mathrm{hpf}$ in larvae exposed to PBDE 47 (500 and $5000 \mathrm{ng} / \mathrm{l}$ ). Statistically significant differences from control are indicated by asterisks (Dunnett's tests, $p<0.05$ ). Percentages are provided in parentheses above each bar, and values are presented as mean \pm S.E. (B) The most severely impacted larvae (age $164 \mathrm{hpf}$ ) exposed to PBDE $47(5000 \mu \mathrm{g} / \mathrm{l})$ from 3 to 23 hpf exposure developed an abnormal dorsally curved tail, but still showed normal inflation of the swim bladed (arrows). Scale bar $=1 \mathrm{~mm}$.

Weiss and Wertman, 1978; Deane and Segal, 1979). However, in cases of cardiac dysfunction arising from specific genetic lesions or chemical cardiotoxicity, dorsal curvature is clearly preceded by reduction in cardiac output. With PBDE 47 exposure, dorsal curvature preceded the onset of tachycardia, and even in early phases of tachycardia (before the development of arrhythmia) there were no signs of reduced cardiac output (e.g. edema). Moreover, larvae with dorsal curvature due to a primary cardiac defect do not develop flexion at the hindbrain (see Fig. 3F; Incardona et al., 2004, 2006). Instead, the reduced movement of fluorescent dextran through the CSF suggests a primary neural defect that leads to altered hydrostatic pressure in the CNS. Severe reductions in cardiac output during fish development result in a failure of brain ventricle expansion (Schier et al., 1996; Lowery and Sive, 2005), while severe reductions in CSF flow result in hydrocephaly (Kramer-Zucker et al., 2005). The reduced CSF flow in the absence of hydrocephaly in PBDE 47exposed larvae suggests that CSF production or secretion may be impacted, possibly due to local circulation changes within the hindbrain. In this regard, it is notable that PBDE 47-exposed larvae resemble the zebrafish brain mutant turned on, which shows a mildly reduced hindbrain ventricle and develops dorsal body curvature and flexion at the hindbrain by $6 \mathrm{dpf}$ (Schier et al., 1996).

Second, the timing of the cardiac effects of PBDE 47 exposure is consistent with changes in the autonomic regulation of the heart. In zebrafish embryos prior to about $72 \mathrm{hpf}$, cardiac function (e.g. heart rate, contractility) is driven by intrinsic processes, and does not come under extrinsic influence from autonomic input or nitric oxide signaling until later in the larval period (Fritsche et al., 2000; Pelster et al., 2005; Schwerte et al., 2006). Chemicals that directly impact myocardial targets generally produce cardiac dysfunction in the range of 24-48 hpf, including PAHs (Incardona et al., 2004, 2005, 2006), dioxins (Antkiewicz et al., 2005), and cardioactive pharmaceuticals (Langheinrich et al., 2003; Milan et al., 2003). Heart rate in zebrafish first becomes sensitive to externally applied adrenergic agonist at $72 \mathrm{hpf}$, and externally applied acetylcholine at $96 \mathrm{hpf}$ (Schwerte et al., 2006). However, the M2 muscarinic acetylcholine receptor is expressed in the developing heart by $36 \mathrm{hpf}$, and morpholino knockdown of this receptor produced tachycardia by $72 \mathrm{hpf}$ (Hsieh and Liao, 2002). Therefore a tachycardia appearing at $96 \mathrm{hpf}$ could result from reduced cholinergic input or an excess of adrenergic input. PBDE 47 therefore potentially alters the development of the vagal or sympathetic inputs to the heart. However, a preliminary analysis of islet 1-GFP transgenic zebrafish larvae (Higashijima et al., 2000) exposed to PBDE 47 showed no gross changes in either the vagal innervation of the heart or the distribution of vagal motor neuron cell bodies in the hindbrain (data not shown). We therefore cannot rule out a neurochemical effect of PBDE 47 on neurotransmitter levels or receptor activity (either cholinergic or adrenergic), a postganglionic effect on the heart (i.e., cardiac acetylcholine receptors), or subtle alterations in development of autonomic preganglionic fibers, particularly those arising from the hindbrain.

In zebrafish, the thyroid gland differentiates between 40 and 70 hpf (Rohr and Concha, 2000; Alt et al., 2006) and is functional by $72 \mathrm{hpf}$ (Brown, 1997), but the roles of thyroid hormone during zebrafish development are otherwise not well characterized. Nevertheless, other than lack of swim bladder inflation, there is little overlap between the effects of PBDE 47 exposure and treatment of zebrafish embryos with goitrogens or the phenotype of mutants that lack normal thyroid gland development (Liu and Chan, 2002; Elsalini and Rohr, 2003). It is important, however, to note that exposure to other thyroid-disrupting contaminants (i.e., PCBs) rarely produces effects entirely consistent with genetically mediated or goitrogen-induced thyroid hormone deficiencies (Brown et al., 2004; Zoeller et al., 2000). Therefore, in the absence of specific assays for thyroid function, we cannot rule out an endocrine-disrupting effect of PBDE 47.

Additional studies are needed to fully identify the mechanisms responsible for the developmental toxicity of PBDE 47. Yet by identifying a repeatable suite of morphological and phys- 
iological defects caused by PBDE 47 exposure, we now provide a starting point for future studies to investigate whether these toxic effects result from PBDEs impacting cholinergic function, thyroid pathways, or some other physiological mechanism. It is likely that considerable insight may be gained by a combination of pharmacological studies and a more detailed neuroanatomical analysis, a process that should be greatly enhanced by the tools available with the zebrafish model.

\subsection{Relevance to exposure to PBDE contaminants in the wild}

In the current study, zebrafish embryos and larvae were exposed to PBDE 47 via water, and thus the primary routes for PBDE 47 uptake by larvae were likely through the gills into blood circulation or through direct dermal absorption. In the natural environment, however, PBDEs do not reach high concentrations in surface waters due to their high lipophilicity, and thus the main route of exposure to PBDEs is likely dietary. The lipophilic properties of PBDEs cause them to sequester in lipidrich animal tissues. Similar to other lipophilic contaminants such as PCBs and DDT, PBDEs have been shown to bioaccumulate with increases in trophic level (Law et al., 2003). For juvenile and adult fish, the main exposure route to PBDEs is thus likely to be through consumption of PBDE-contaminated prey. At the earliest stages of development, however, maternal-transfer through lipid stores of the egg can be a significant pathway for embryonic exposure to lipophilic contaminants such as PBDEs.

The concentrations of PBDE 47 required to induce a consistent and reproducible phenotype in zebrafish over this short developmental period were high, especially relative to the tissue concentrations that have been recorded in people and animals in the wild. Using our measured whole-body concentrations of PBDE 47 (Table 1) and known whole-body lipid masses for larval zebrafish (Petersen and Kristensen, 1998), we calculate that the body burden of PBDE 47 in zebrafish larvae from the $500 \mu \mathrm{g} / 1$ PBDE 47 treatment was 2,090,909 ng PBDE $47 \mathrm{~g}^{-1}$ lipid. In the wild, measurements of PBDE levels in eggs and embryos of wildlife are generally lacking. However, some of the highest total PBDE levels recorded in adult marine mammals (4950 ng PBDE per gram lipid; She et al., 2002), birds (7510 ng PBDE per gram lipid; Norstrom et al., 2002), and fishes (7200 ng per gram lipid; Hale et al., 2001) (for review, see Hites, 2004) are considerably lower than the tissue levels required to cause developmental toxicity here. It is important to note, however, that this study was a phenotypic screen offish embryos exposed to a common PBDE congener and was therefore not designed to evaluate toxicological responses at low, environmentally realistic exposure concentrations. In similar work, Hornung et al. (1996) did not observe any toxicity effects of PBDE 47 when the compound was injected into rainbow trout (Oncorhynchus mykiss) eggs at concentrations up to $12 \mu \mathrm{g} / \mathrm{g}$, suggesting that environmental PBDEs may not yet reach the levels necessary to produce developmental defects in wild fish species.

Furthermore, we administered only PBDE 47 to developing fish embryos since this congener is often the most common PBDE compound detected in animal tissues (Hale et al., 2001;
Brown et al., 2006; Ikonomou et al., 2006; for review, see Hites, 2004). Animals in the wild, however, are exposed to a suite of PBDE forms and other PBDE congeners may be more potent in their biological effects. Recent evidence indicates that PBDEs can be biotransformed from one congener to another and to hydroxylated forms (Kierkegaard et al., 1999; Stapleton et al., 2004a,b; Tomy et al., 2004), and future work should explore whether these hydroxylated PBDEs could in part mediate the toxicity of PBDE 47 seen in larval zebrafish.

\section{Conclusions}

Here, we provide the first evidence that embryonic exposure to PBDE 47 can result in the development of morphological, cardiac and neural deficits that impair survivorship for fish larvae. The concentration of PBDE 47 required to cause acute developmental toxicity was considerably higher than the tissue concentrations that have been record in animals and people to date. Nevertheless, now that we have identified consistent developmental alterations caused by PBDE 47 exposure, future studies have a foundation for exploring the cellular and physiological mechanisms by which PBDE 47 exerts these effects. Furthermore, this developmental toxicity was seen in zebrafish at high doses of PBDE 47 under controlled laboratory conditions, and more work is needed to examine whether similar developmental impacts might occur in native species under long-term exposure to lower PBDE concentrations.

\section{Acknowledgements}

This publication was supported by the West Coast Center for Oceans and Human Health as part of the NOAA Oceans and Human Health Initiative, WCCOHH publication no. 10. The WCCOHH is part of the National Marine Fisheries Service's Northwest Fisheries Science Center, Seattle, WA. The authors thank Amy Cattle, Heather Day, Jamie Colman, and Tiffany Linbo for technical assistance. The authors also thank Jamie Colman and Walt Dickhoff, and two anonymous referees, whose comments greatly improved the quality of this manuscript.

\section{References}

Alaee, M., Arias, P., Sjödin, A., Bergman, Å., 2003. An overview of commercially used brominated flame retardants, their applications, their use patterns in different countries/regions and possible modes of release. Environ. Int. 29, 683-689.

Alt, B., Reibe, S., Feitosa, N.M., Elsalini, O.A., Wendl, T., Rohr, K.B., 2006. Analysis of origin and growth of the thyroid gland in zebrafish. Dev. Dyn. 235, 1872-1883.

Antkiewicz, D.S., Burns, C.G., Carney, S.A., Peterson, R.E., Heideman, W., 2005. Heart malformation is an early response to TCDD in embryonic zebrafish. Toxicol. Sci. 84, 368-377.

Bayen, S., Thomas, G.O., Lee, H.K., Obbard, J.P., 2003. Occurrence of polychlorinated biphenyls and polybrominated diphenyl ethers in green mussels (Perna viridis) from Singapore, Southeast Asia. Environ. Toxicol. Chem. 22, 2432-2437.

Bello, S.M., Heiderman, W., Peterson, R.E., 2004. 2,3,7,8-Tetrachlorodibenzo$\rho$-dioxin inhibits regression of the common cardinal vein in developing zebrafish. Toxicol. Sci. 78, 258-266. 
Birnbaum, L.S., Staskal, D.F., 2004. Brominated flame retardants: cause for concern? Environ. Health Perspect. 112, 9-17.

Blechinger, S.R., Warren Jr., J.T., Kuwada, J.Y., Krone, P.H., 2002. Developmental toxicology of cadmium in living embryos of a stable transgenic zebrafish line. Environ. Health Perspect. 110, 1041-1046.

Branchi, I., Capone, F., Vitalone, A., Madia, F., Santucci, D., Alleva, E., Costa, L.G., 2005. Early developmental exposure to BDE 99 or aroclor 1254 affects neurobehavioural profile: interference from the administration route. Neurotoxicology 26, 183-192.

Brown, D.D., 1997. The role of thyroid hormone in zebrafish and axolotl development. Proc. Natl. Acad. Sci. U.S.A. 94, 13011-13016.

Brown, S.B., Adams, B.A., Cyr, D.G., Eales, J.G., 2004. Contaminant effects on the teleost fish thyroid. Environ. Toxicol. Chem. 23, 1680-1701.

Brown, F.R., Winkler, J., Visita, P., Dhaliwal, J., Petreas, M., 2006. Levels of PBDEs, PCDDs, PCDFs, and coplanar PCBs in edible fish from California coastal waters. Chemosphere 64, 276-286.

Carey, M.E., Vela, A.R., 1974. Effect of systemic arterial hypotension on the rate of cerebrospinal fluid formation in dogs. J. Neurosurg. 41, 350-355.

Ciparis, S., Hale, R.C., 2005. Bioavailability of polybrominated diphenyl ether flame retardants in biosolids and spiked sediment to the aquatic oligochaete, Lumbriculus variegatus. Environ. Toxicol. Chem. 24, 916-925.

Darnerud, P.O., Eriksen, G.S., Jóhannesson, T., Larsen, P.B., Viluksela, M., 2001. Polybrominated diphenyl ethers: occurrence, dietary exposure, and toxicology. Environ. Health Perspect. 109 (Suppl. 1), 49-68.

Deane, R., Segal, M.B., 1979. The effect of vascular perfusion of the choroid plexus on the secretion of cerebrospinal fluid. J. Physiol. 293, 18P-19P.

De Boer, J., Wester, P.G., Klamer, H.J.C., Lewis, W.E., Boon, J.P., 1998. Do flame retardants threaten ocean life? Nature 394, 28-29.

de Wit, C.A., Alaee, M., Muir, D.C.G., 2006. Levels and trends of brominated flame retardants in the Arctic. Chemosphere 64, 209-233.

Domingo, J.L., Bocio, A., Falcó, G., Llobet, J.M., 2006. Exposure to PBDEs and PCDEs associated with the consumption of edible marine species. Environ. Sci. Technol. 40, 4394-4399.

Dufault, C., Poles, G., Driscoll, L.L., 2005. Brief postnatal PBDE exposure alters learning and the cholinergic modulation of attention in rats. Toxicol. Sci. 88, 172-180.

Elsalini, O.A., Rohr, K.B., 2003. Phenylthiourea disrupts thyroid function in developing zebrafish. Dev. Genes Evol. 212, 593-598.

Eriksson, P., Viberg, H., Jakobsson, E., Örn, U., Fedricksson, A., 2002. A brominated flame retardant, 2,2',4,4',5-pentabromodiphenyl ether: uptake, retention, and induction of neurobehavioral degrangement in mice during a critical phase of neonatal brain development. Toxicol. Sci. 67, 98-103.

Fängström, B., Athanasiadou, M., Athanassiadis, I., Bignert, A., Grandjean, P., Weihe, P., Bergman, Å., 2005. Polybrominated diphenyl ethers and traditional organochlorine pollutants in fulmars (Fulmarus glacialis) from the Faroe Islands. Chemosphere 60, 836-843.

Fernie, K.J., Shutt, J.L., Mayne, G., Hoffman, D., Letcher, R.J., Drouillard, K.G., Ritchie, I.J., 2005. Exposure to polybrominated diphenyl ethers (PBDEs): changes in thyroid, vitamin A, glutathione homeostatis, and oxidative stress in American kestrels (Falco sparverius). Toxicol. Sci. 88, 375-383.

Fritsche, R., Schwerte, T., Pelster, B., 2000. Nitric oxide and vascular reactivity in developing zebrafish, Danio rerio. Am. J. Physiol. Regul. Integr. Comp. Physiol. 279, R2200-R2207.

Haendel, M.A., Tilton, F., Bailey, G.S., Tanguay, R.L., 2004. Developmental toxicity of the dithiocarbamate pesticide sodium metam in zebrafish. Toxicol. Sci. 81, 390-400.

Hale, R.C., LaGuardia, M.J., Harvey, E.P., Mainor, T.M., Duff, W.H., Gaylor, M.O., 2001. Polybrominated diphenyl ether flame retardants in Virginia freshwater fishes (USA). Environ. Sci. Technol. 35, 4585-4591.

Hale, R.C., Alaee, M., Manchester-Neesvig, J.B., Stapleton, H.M., Ikonomou, M.G., 2003. Polybrominated diphenyl ether flame retardants in the North American environment. Environ. Int. 29, 771-779.

Hallgren, S., Sinjari, T., Håkansson, H., Darnerud, P.O., 2001. Effects of polybrominated diphenyl ethers (PBDEs) and polychlorinated biphenyls (PCBs) on thyroid hormone and vitamin A levels in rats and mice. Arch. Toxicol. 75, 200-208.

Hallgren, S., Darnerud, P.O., 2002. Polybrominated diphenyl ethers (PBDEs), polychlorinated biphenyls (PCBs) and chlorinated paraffins (CPs) in rats- testing interactions and mechanisms for thyroid hormone effects. Toxicology 177, 227-243.

He, J., Robrock, K.R., Alvarez-Cohen, L., 2006. Microbial reductive debromination of polybrominated diphenyl ethers (PBDEs). Environ. Sci. Technol. 40, 4429-4434.

Higashijima, S., Hotta, Y., Okamoto, H., 2000. Visualization of cranial motor neurons in live transgenic zebrafish expressing green fluorescent protein under the control of the islet-1 promoter/enhancer. J. Neurosci. 20, 206-218.

Hill, A.J., Teraoka, H., Heideman, W., Peterson, R.E., 2005. Zebrafish as a model vertebrate for investigating chemical toxicity. Toxicol. Sci. 86, 6-19.

Hinton, D.E., Kullman, S.W., Hardman, R.C., Volz, D.C., Chen, P.-J., Carney, M., Bencic, D.C., 2005. Resolving mechanisms of toxicity while pursuing ecotoxicological relevance? Mar. Poll. Bull. 51, 635-648.

Hites, R.A., 2004. Polybrominated diphenyl ethers in the environment and in people: a meta-analysis of concentrations. Environ. Sci. Technol. 38, 945-956.

Hornung, M.W., Zabel, E.W., Peterson, R.E., 1996. Toxic equivalency factors of polybrominated dibenzo- $\rho$-dioxin, dibenzofuran, biphenyl, and polyhalogenated diphenyl ether congeners based on rainbow trout early life stage mortality. Toxicol. Appl. Pharmacol. 140, 227-234.

Hsieh, D.J.-Y., Liao, C.-F., 2002. Zebrafish $\mathrm{M}_{2}$ muscarinic acetylcholine receptor: cloning, pharmacological characterization, expression patterns and roles in embryonic bradycardia. Br. J. Pharmacol. 137, 782-792.

Ikonomou, M.G., Fernandez, M.P., Hickman, Z.L., 2006. Spatio-temporal and species-specific variation in PBDE levels/patterns in British Columbia's coastal waters. Environ. Pollut. 140, 355-363.

Ikonomou, M.G., Rayne, S., Addison, R.F., 2002. Exponential increases of the brominated flame retardants, polybrominated diphenyl ethers, in the Canadian Arctic from 1981 to 2000. Environ. Sci. Technol. 36, 1886-1892.

Incardona, J.P., Collier, T.K., Scholz, N.L., 2004. Defects in cardiac function precede morphological abnormalities in fish embryos exposed to polycyclic aromatic hydrocarbons. Toxicol. Appl. Pharmacol. 196, 191-205.

Incardona, J.P., Carls, M.G., Teraoka, H., Sloan, C.A., Collier, T.K., Scholz, N.L., 2005. Aryl hydrocarbon receptor-independent toxicity of weathered crude oil during fish development. Environ. Health Perspect. 113, 1755-1762.

Incardona, J.P., Day, H.L., Collier, T.K., Scholz, N.L., 2006. Developmental toxicity of 4-ring polycyclic aromatic hydrocarbons in zebrafish is differentially dependent on $\mathrm{AH}$ receptor isoforms and hepatic cytochrome P450 1A metabolism. Toxicol. Appl. Pharmacol. 217, 308-321.

Johnson-Restrepo, B., Kannan, K., Addink, R., Adams, D.H., 2005. Polybrominated diphenyl ethers and polychlorinated biphenyls in a marine foodweb of coastal Florida. Environ. Sci. Technol. 39, 8243-8250.

Julander, A., Karlsson, M., Hagström, K., Ohlson, C.G., Engwall, M., Bryngelsson, I.-L., Westberg, H., van Bavel, B., 2005. Polybrominated diphenyl ethers-plasma levels and thyroid status of workers at an electronic recycling facility. Int. Arch. Occup. Environ. Health 78, 584-592.

Kierkegaard, A., Balk, L., Tjärnlund, U., DeWit, C.A., Jansson, B., 1999. Dietary uptake and biological effects of decabromodiphenyl ether in rainbow trout (Oncorhynchus mykiss). Environ. Sci. Technol. 33, 1612-1617.

Kimmel, C.B., Ballard, W.W., Kimmel, S.R., Ullmann, B., Schilling, T.F., 1995. Stages of embryonic development of the zebrafish. Dev. Dyn. 203, 253-310.

Kramer-Zucker, A.G., Olale, F., Haycraft, C.J., Yoder, B.K., Schier, A.F., Drummond, I.A., 2005. Cilia-driven fluid flow in the zebrafish pronephros, brain and Kupffer's vesicle is required for normal organogenesis. Development 132, 1907-1921.

Langheinrich, U., Vacun, G., Wagner, T., 2003. Zebrafish embryos express an orthologue of HERG and are sensitive toward a range of QT-prolonging drugs inducing severe arrhythmia. Toxicol. Appl. Pharmacol. 193, 370-382.

Law, R.J., Alaee, M., Allchin, C.R., Boon, J.P., Lebeuf, M., Lepom, P., Stern, G.A., 2003. Levels and trends of polybrominated diphenylethers and other brominated flame retardants in wildlife. Environ. Int. 29, 757-770.

Lefebvre, K.A., Trainer, V.L., Scholz, N.L., 2004. Morphological abnormalities and sensorimotor deficits in larval fish exposed to dissolved saxitoxin. Aquat. Toxicol. 66, 159-170.

Lilienthal, H., Roth-Härer, A., Hack, A., Altmann, L., Winneke, G., 2005. Developmental neurotoxicity of PHAHs: endocrine-mediated and general behavioral endpoints in adult male rats. Environ. Toxicol. Pharmacol. 19, 757-759. 
Linbo, T.L., Stehr, C.M., Incardona, J.P., Scholz, N.L., 2006. Dissolved copper triggers cell death in the peripheral mechanosensory system of larval fish. Environ. Toxicol. Chem. 25, 597-603.

Liu, Y.-W., Chan, W.-K., 2002. Thyroid hormones are important for embryonic to larval transitory phase in zebrafish. Differentiation 70, 36-45.

Lowery, L.A., Sive, H., 2005. Initial formation of zebrafish brain ventricles occurs independently of circulation and requires the nagie oko and snakehead/atpala.1 gene products. Development 132, 2057-2067.

Mashayekhi, F., Draper, C.E., Pourghasem, M., Bannister, C.M., Owen-Lynch, P.J., Miyan, J.A., 2002. Deficient cortical development in the hydrocephalic Texas (H-Tx) rat: a role for cerebrospinal fluid. Brain 125, 1859-1874.

McDonald, T.A., 2002. A perspective on the potential health risks of PBDEs. Chemosphere 46, 745-755.

Milan, D.J., Peterson, T.A., Ruskin, J.N., Peterson, R.T., MacRae, C.A., 2003. Drugs that induce repolarization abnormalities cause bradycardia in zebrafish. Circulation 107, 1355-1358.

Miyan, J.A., Nabiyouni, M., Zendah, M., 2003. Development of the brain: a vital role for cerebrospinal fluid. Can. J. Physiol. Pharmacol. 81, 317-328.

Norstrom, R.J., Simon, M., Moisey, J., Wakeford, B., Weseloh, D.V.C., 2002. Geographic distribution (2000) and temporal trends (1981-2000) of brominated diphenyl ethers in Great Lake herring gull eggs. Environ. Sci. Technol. 36, 4783-4789.

Owen-Lynch, P.J., Draper, C.E., Mashayekhi, F., Bannister, C.M., Miyan, J.A., 2003. Defective cell cycle control underlies abnormal cortical development in the hydrocephalic Texas rat. Brain 126, 623-631.

Pelster, B., Grillitsch, S., Schwerte, T., 2005. NO as a mediator during the early development of the cardiovascular system in the zebrafish. Comp. Biochem. Physiol. A 142, 215-220.

Petersen, G.I., Kristensen, P., 1998. Bioaccumulation of lipophilic substances in fish early life stages. Environ. Toxicol. Chem. 17, 1385-1395.

Rayne, S., Ikonomou, M.G., Antcliffe, B., 2003. Rapidly increasing polybrominated diphenyl ether concentrations in the Columbia River system from 1992 to 2000. Environ. Sci. Technol. 37, 2847-2854

Rohr, K.B., Concha, M.L., 2000. Expression of $n k 2.1 a$ during early development of the thyroid gland in zebrafish. Mech. Dev. 95, 267-270.

Schecter, A., Päpke, O., Tung, K.C., Joseph, J., Harris, T.R., Dahlgren, J., 2005. Polybrominated diphenyl ether flame retardants in the U.S. population: current levels, temporal trends, and comparison with dioxins, dibenzofurans, and polychlorinated biphenyls. J. Occup. Environ. Med. 47, 199-211.

Schecter, A., Pavuk, M., Päpke, O., Ryan, J.J., Birnbaum, L., Rosen, R., 2003. Polybrominated diphenyl ethers (PBDEs) in U.S. mothers' milk. Environ. Health Perspect. 111, 1723-1729.

Schier, A.F., Neuhauss, S.C., Harvey, M., Malicki, J., Solnica-Krezel, L., Stainier, D.Y., Zwartkruis, F., Abdelilah, S., Stemple, D.L., Rangini, Z., Yang, H., Driever, W., 1996. Mutations affecting the development of the embryonic zebrafish brain. Development 123, 165-178.

Schwerte, T., Prem, C., Mairösl, A., Pelster, B., 2006. Development of the sympatho-vagal balance in the cardiovascular system in zebrafish (Danio rerio) characterized by power spectrum and classical signal analysis. J. Exp. Biol. 209, 1093-1100.

She, J., Petreas, M., Winkler, J., Visita, P., McKinney, M., Kopec, D., 2002. PBDEs in the San Francisco Bay area: measurements in harbor seal blubber and human breast adipose tissue. Chemosphere 46, 697-707.

Stapleton, H.M., Alaee, M., Letcher, R.J., Baker, J.E., 2004a. Debromination of the flame retardant decabromodiphenyl ether by juvenile carp (Cypri- nus carpio) following dietary exposure. Environ. Sci. Technol. 38, 112 119 .

Stapleton, H.M., Letcher, R.J., Baker, J.E., 2004b. Debromination of polybrominated diphenyl ether congeners BDE 99 and BDE 183 in the intestinal tract of the common carp (Cyprinus carpio). Environ. Sci. Technol. 38, 1054-1061.

Stehr, C.M., Linbo, T.L., Incardona, J.P., Scholz, N.L., 2006. The developmental neurotoxicity of fibronil: notochord degeneration and locomotor defects in zebrafish embryos and larvae. Toxicol. Sci. 92, 270-278.

Timme-Laragy, A.R., Levin, E.D., Di Giulio, R.T., 2006. Developmental and behavioral effects of embryonic exposure to the polybrominated diphenylether mixture DE-71 in the killifish (Fundulus heteroclitus). Chemosphere 62, 1097-1104.

Tomy, G.T., Palace, V.P., Halldorson, T., Braekevelt, E., Danell, R., Wautier, K. Evans, B., Brinkworth, L., Fisk, A.T., 2004. Bioaccumulation, biotransformation, and biochemical effects of brominated diphenyl ethers in juvenile lake trout (Salvelinus namaycush). Environ. Sci. Technol. 38, 1496-1504.

Ueno, D., Kajiwara, N., Tanaka, H., Subramanian, A., Fillmann, G., Lam, P.K.S., Zheng, G.J., Muchitar, M., Razak, H., Prudente, M., Chung, K.-H., Tanabe, S., 2004. Global pollution monitoring of polybrominated diphenyl ethers using skipjack tuna as a bioindicator. Environ. Sci. Technol. 38, 2312-2316.

Viberg, H., Fredriksson, A., Eriksson, P., 2005. Deranged spontaneous behaviour and decrease in cholinergic muscatinic receptors in hippocampus in the adult rat, after neonatal exposure to the brominated flame-retardant, 2,2',4,4',5pentabromodiphenyl ether (PBDE 99). Environ. Toxicol. Pharmacol. 20, 283-288.

Viberg, H., Fredriksson, A., Eriksson, P., 2004. Neonatal exposure to the brominated flame-retardant, 2,2',4,4',5-pentabromodiphenyl ether, decreases cholinergic nicotinic receptors in hippocampus and affects spontaneous behaviour in the adult mouse. Environ. Toxicol. Pharmacol. 17, 61-65.

Viberg, H., Fredriksson, A., Jakobsson, E., Örn, U., Eriksson, P., 2003a. Neurobehavioral derangements in adult mice receiving decabrominated diphenyl ether (PBDE 209) during a defined period of neonatal brain development. Toxicol. Sci. 76, 112-120.

Viberg, H., Frediksson, A., Eriksson, P., 2003b. Neonatal exposure to polybrominated diphenyl ether (PBDE 153) disrupts spontaneous behaviour, impairs learning and memory, and decreases hippocampal cholinergic receptors in adult mice. Toxicol. Appl. Pharmacol. 192, 95-106.

Viberg, H., Fredirksson, A., Eriksson, P., 2002. Neonatal exposure to the brominated flame retardant 2,2',4,4',5-pentabromodiphenyl ether causes altered susceptibility in the cholinergic transmitter system in the adult mouse. Toxicol. Sci. 67, 104-107.

Wania, F., Dugani, C.B., 2003. Assessing the long-range transport potential of polybrominated diphenyl ethers: a comparison of four multimedia models. Environ. Toxicol. Chem. 22, 1252-1261.

Weiss, M.H., Wertman, N., 1978. Modulation of CSF production by alterations in cerebral perfusion pressure. Arch. Neurol. 35, 527-529.

Westerfield, M., 1995. The Zebrafish Book: A Guide for the Laboratory Use of Zebrafish (Danio rerio), 3rd ed. University of Oregon Press, Eugene, OR, USA.

Zar, J.H., 1999. Biostatistical Analysis, 4th ed. Prentice-Hall, Inc., New Jersey, $663 \mathrm{pp}$.

Zoeller, R.T., Dowling, A.L., Vas, A.A., 2000. Developmental exposure to polychlorinated biphenyls exerts thyroid hormone-like effects on the expression of RC3/neurogranin and myelin basic protein messenger ribonucleic acids in the developing rat brain. Endocrinology 141, 181-189. 